\title{
Properties of chemically and mechanically isolated fibres of spruce (Picea abies [L.] Karst.). Part 1: Structural and chemical characterisation
}

\author{
Ingo Burgert', Notburga Gierlinger ${ }^{1}$ and Tanja \\ Zimmermann $^{2}$ \\ ${ }^{1}$ Department of Biomaterials, Max-Planck-Institute of \\ Colloids and Interfaces, 14424 Potsdam, Germany \\ 2 Empa-Materials Science and Technology, Wood \\ Science/Biometrics, Dübendorf, Switzerland \\ ${ }^{*}$ Corresponding author. \\ E-mail: ingo.burgert@mpikg-golm.mpg.de
}

\begin{abstract}
Single fibres of spruce (Picea abies [L.] Karst.) were isolated both chemically and mechanically from a solid wood sample. Mechanical isolation was carried out using very fine tweezers to peel out fibres, thereby taking advantage of the low shear strength between them. Chemical isolation was achieved using hydrogen peroxide and glacial acetic acid. Fibres were examined with Fourier-transform infrared (FT-IR) microscopy, and fieldemission environmental scanning electron microscopy (FE-ESEM) in low-Vacuum mode to compare the isolation techniques with respect to their influence on cell wall structure and polymer assembly. The chemical treatment led to degradation of lignin and hemicelluloses, significantly influencing the cell wall assembly and structure. The cell wall polymers of mechanically isolated fibres remained in their natural constitution. As expected, the peeling process caused separation of cell wall layers. Our examinations indicate that delamination predominately took place at the interface between the secondary cell wall and the compound middle lamella. However, fracture between the S1 and S2 layers was examined as well. With respect to fibre quality, it was of particular importance that transverse crack propagation in the secondary cell walls (S2) was not observed.
\end{abstract}

Keywords: chemically isolated fibres; field-emission environmental scanning electron microscopy (FE-ESEM); Fourier-transform infrared (FT-IR) microscopy; mechanically isolated fibres; structure.

\section{Introduction}

The structure and mechanical properties of individual wood fibres are of particular interest regarding the demands of pulp and paper, as well as fibreboard production. One of the first systematic studies on single fibres were carried out by Jayne $(1959,1960)$, who tested earlywood and latewood fibres of 10 gymnosperm species. The main objectives of a multitude of investigations were either to correlate stress-strain behaviour of single fibres with structural features, e.g., microfibril angle in the S2 layer (Page and El-Hosseiny 1983; Sedighi-Gilani and Navi 2004) or to detect and distinguish material- and process-related failures of single fibres (Page et al. 1977; Mott et al. 1995; Shaler et al. 1996; Nyholm et al. 2001). In a highly systematic study on loblolly pine (Groom et al. 2002a,b; Mott et al. 2002) the relevance of stem position to fibre properties was illustrated. Apart from the general differences between juvenile and adult wood, the authors were able to provide a detailed map of fibre properties along the tree stem.

Besides wood fibre research related to utilisation aspects, the fibrous structure of wood has become of interest in biomaterials science, with focus on learning from the hierarchically organised structure and from specific molecular mechanistic phenomena at the cell wall level (Jeronimidis 2000; Fratzl 1999, 2003; Keckes et al. 2003). In order to clearly separate deformation mechanisms inside the cell wall from those mediated by cellcell interactions, both wood tissue and single fibres have to be studied in two-fold approaches (Burgert and Frühmann 2004). However, for comparative studies between the mechanical properties of wood tissues and isolated cells, fibres with a natural cell wall assembly are required. Naturally, the fibre constitution depends decisively on pre-treatments used for fibre isolation. The use of unspecific chemical treatment results in fibres that are not only separated at the middle lamella, but with cell wall polymers that are also partly degraded. These modifications are of minor importance as long as fibre properties are compared directly. However, investigations into the hierarchical structure of wood and the mechanical interaction of the cell wall polymers require single fibres with an unmodified cell wall assembly.

In a previous paper (Burgert et al. 2002), a technique for isolating fibres mechanically was introduced for the first time. Fibres were separated using very fine tweezers in a peeling process, taking advantage of the low shear strength between them. As a chemical treatment step was avoided completely, the cell wall polymers were retained in their original condition. However, mechanical impact by the isolation technique was likely and, therefore, first proof of the fibre quality was determined by polarised light microscopy at that time.

In this paper and two subsequent ones, fibre properties are studied in more detail. The main objective of the first paper is to compare structural and chemical properties of chemically and mechanically isolated fibres using field-emission environmental scanning electron microscopy (FE-ESEM) in the low-vacuum mode as well as Fourier-transform infrared (FT-IR) microscopy. In the second paper (Burgert et al. 2005) further structural cha- 
racterisation of the cell wall is reported, with the main focus on the twisting behaviour of isolated fibres during the drying processes. The third paper (Part 3: submitted for publication) deals with mechanical aspects. Tensile properties of mechanically and chemically isolated fibres were compared by microtensile investigations (see Burgert et al. 2003).

\section{Materials and methods}

Material was taken from the adult wood of a 120 -year-old spruce tree (Picea abies [L.] Karst.) grown near Vienna, Austria. A small wood block (R, $15 \mathrm{~mm} ; \mathrm{T}, 15 \mathrm{~mm}$;, $15 \mathrm{~mm}$ ) was selected from adult wood at the bottom of the trunk. The block was fixed in a microtome and 200- $\mu \mathrm{m}$-thick slices (LT plane) were sectioned along the growth rings. Slices from the "late transition wood zone" between pure earlywood and latewood were taken for further investigations. Since the growth rings showed a gradient transition from earlywood to latewood and contained only a few very dense latewood cell rows, it was expected that the region for rather homogenous cell sizes should be found in the "late transition zone" of the growth ring.

A tangential slice was fixed under a light microscope and single fibres were isolated using very fine tweezers (Burgert et al. 2002). Matched to the single fibres, fibre bundles were taken out for chemical maceration. For chemical maceration, a treatment with hydrogen peroxide and glacial acetic acid was chosen (Ander and Nyholm 2000; Groom et al. 2002a). In order to separate fibres as gently as possible, optimisation tests were first carried out, adapting the concentration and treatment time. From these studies, it was found that $31.3 \%$ hydrogen peroxide and $99.8 \%$ glacial acetic acid at a ratio of $1: 1$, and a temperature of $60^{\circ} \mathrm{C}$ required $25.5 \mathrm{~h}$ for the fibres to adequately separate. Subsequently, fibres were washed carefully in distilled water several times.

Two different approaches were chosen to study the influence of the isolation technique on the cell wall structure of single fibres. On one hand, structural investigations were carried out in the low-vacuum mode of FE-ESEM. The low-vacuum mode allows a pressure of approximately 0.75 Torr while investigating the unsputtered surface of a fibre. On the other hand, the chemical composition of mechanically and chemically isolated fibres was investigated using an FT-IR microscope (Hyperion 3000) equipped with a liquid nitrogen-cooled mercury cadmium telluride (MCT) detector and connected to an Equinox 55 FT-IR spectrometer (Bruker GmbH, Germany, http://www.bruker.de). Transmission spectra with a spectral resolution of $4 \mathrm{~cm}^{-1}$ were acquired from single air-dried wood fibres placed on BaF windows. Nine sample spectra were measured along each fibre using an aperture of $20 \mu \mathrm{m} \times 100 \mu \mathrm{m}$. A total of 256 scans were co-added per sample spectrum and apodised, applying the Blackman-Harris three-term function and a zero filling factor of 2. For comparison of mechanically and chemically isolated fibres, the spectra from two fibres were always averaged (18 sample spectra).

In order to quantify approximately cell wall modifications, the mass loss during chemical isolation treatment was examined. The weight of three spruce samples, after drying treatment at $103^{\circ} \mathrm{C}$ in an oven, was measured before and after the chemical isolation.

\section{Results and discussion}

\section{Low-vacuum FE-ESEM examinations}

The influence of the isolation technique on the structural properties of fibres at the cell level was examined in scanning electron microscopy studies. In Figure 1, images of chemically isolated fibres are shown at various levels of magnification.

The chemically isolated fibres lost their rectangular shape and partly collapsed. This is due to significant twisting of the fibres while drying (Burgert et al. 2005). At the surface of the fibres, threads oriented in parallel can be detected, which should be related to the cellulose microfibril orientation in the cell wall (Figure 1A-C). The parallel texture means it is reasonable to assume that the secondary cell wall layers were exposed. Apparently, the orientation of the threads corresponded with the microfibril angle in the S2 layer of normal adult wood fibres.

Figure $1 b$ shows small kinks in the fibre, which might be caused by fibre handling or by events that occurred previously in the living tree (Nyholm et al. 2001). If the small kinks were due to fibre manipulation after chemical treatment, this points to a loss of mechanical stability of the fibre caused by modification of the cell wall assembly. In Figure 1D the former connection to a ray is shown, where the cross-section of the fibre is reduced significantly. Besides the cross-field pits, a bordered pit can be detected, according to the heterocellular structure of spruce rays.

In Figure 2 the surface structure of mechanically isolated fibres is shown at various magnifications. Obviously, since the fibres were separated in a peeling process, cell wall layers have been exposed to mechanical stresses. With respect to microtensile examinations of mechanically isolated fibres (see Part 3: submitted for publication) it is of prime importance to know which cell wall layers are affected, or rather to exclude the possibility that, in particular, the S2 layer was damaged by the peeling process.

In Figure 2A a spruce tracheid is shown with a typical cell wall structure after mechanical isolation. In contrast to the chemically macerated fibres, the mechanically isolated fibres maintained a rectangular shape, indicating that the rigid cell wall assembly still exists. A bordered pit can be detected on one side of the fibre. The surface of the other side shows a covering layer with frayed edges. At the right-hand side at the cell corner below the bordered pit, a wadded structure can be observed. This type of additional layer can be attached as a wadded structure, as shown in Figure 2A, or as a thin layer with a laminar shape, as shown in Figure 2D. Generally, they are partially connected to isolated fibres at their cell corners. Apparently, by peeling the fibre out of the tissue, segments of the cell wall of former matched cells are also pulled out. Vice versa, parts of the cell wall of the fibre of interest were removed as well.

Figure 2B shows a segment of a fibre in detail with a torn covering layer. The most striking features of the covering layer are the frayed edges and the surface structure. In contrast to chemically isolated fibres, threads with a parallel orientation cannot be detected at the surface of the covering layer. In Figure $2 \mathrm{C}$ two bordered pits and the surrounding cell wall structure are shown. The covering layer is fractured between the bordered pits and above the pit on the right-hand side. In this case no frayed edges can be detected. Cracks propagated 

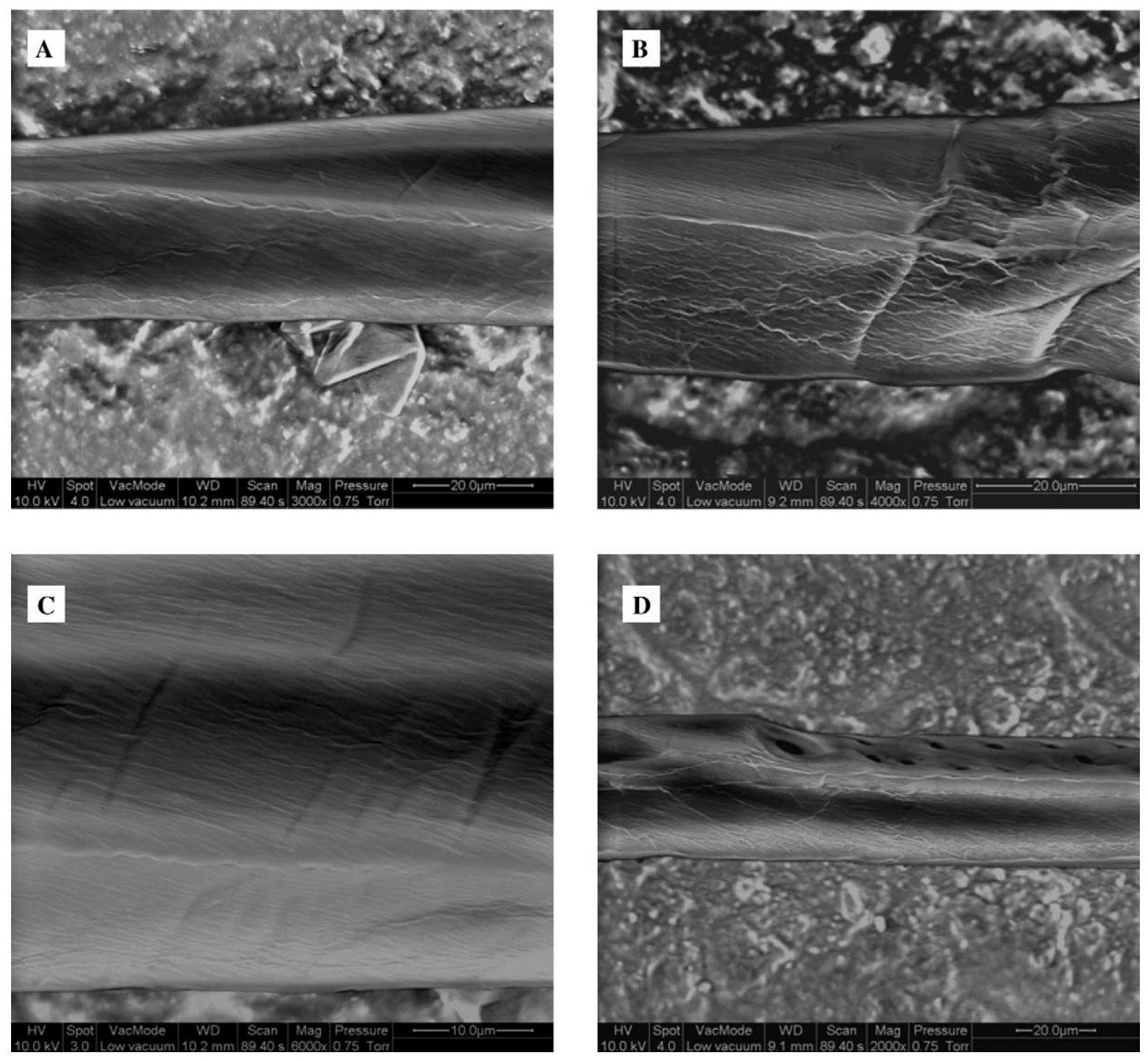

Figure 1 FE-ESEM images in the low-vacuum mode of chemically isolated spruce fibres shown at various levels of magnification.

through the covering layer and a small part of one bordered pit was pulled off, but the cell wall structure underneath seems to be undamaged. In Figure 2D the cell wall structure underneath is shown in a fibre segment, where the covering layer was removed completely (except from the cell corner where additional segments of former matches cells are located). Threads are visible that are oriented almost parallel to the longitudinal direction. The fracture surface is rather smooth and shows no fringes caused by crack propagation. Figure $2 \mathrm{E}$ reveals that the covering layer is without any texture. Underneath, two cell wall layers can be detected. Close to the frayed edges of the covering layer, a small ribbon of a layer is exposed. Above a cell wall with strongly parallel orientation, thread-like bundles can be observed. The angle of the threads with regard to the cell axis is approximately $50^{\circ}$. The higher magnification in Figure $2 \mathrm{~F}$ allows a more detailed view of the parallel texture. In this case the angle of the threads is approximately $40^{\circ}$. The bundles have a diameter of approximately $0.5 \mu \mathrm{m}$. Above the smooth fracture surface, a covering layer is again evident in a wrinkled condition.

By combining the information of all six images, conclusions on the influence of the peeling process on the cell wall assembly of the isolated fibres can be drawn. The images show that predominately plane fracture surfaces are produced by the peeling process. The structure and thickness of the covering layer could be only roughly estimated, but coincide with the thickness of the compound middle lamella (primary wall and middle lamella) as reported in the literature (Bodig and Jayne 1982; Bergander and Salmén 2002). The exposed cell wall layers beneath the covering layer show a predominately parallel alignment of threads. Assuming that the threads correspond to agglomerated cellulose bundles, a cellulose microfibril angle of approximately $50^{\circ}$ can be presumed (Figure 2E,F). Since the microfibril angle in the S2 layer of adult wood fibres of spruce should be significantly smaller (Lindström et al. 1998; Lichtenegger et al. 2003), it seems reasonable to assume that the exposed surfaces show the $\mathrm{S} 1$ layer, even though it cannot be observed if cellulose microfibrils are wound alternately (Kataoka et al. 1992). Thus, the crack predominately separated the compound middle lamella and the S1 layer. Donaldson (1995) split radiata pine samples with a chisel and observed fracture predominately between the primary wall and the S1 layer and within the S1 layer (for samples with a normal lignin distribution). However, Figure 1D 

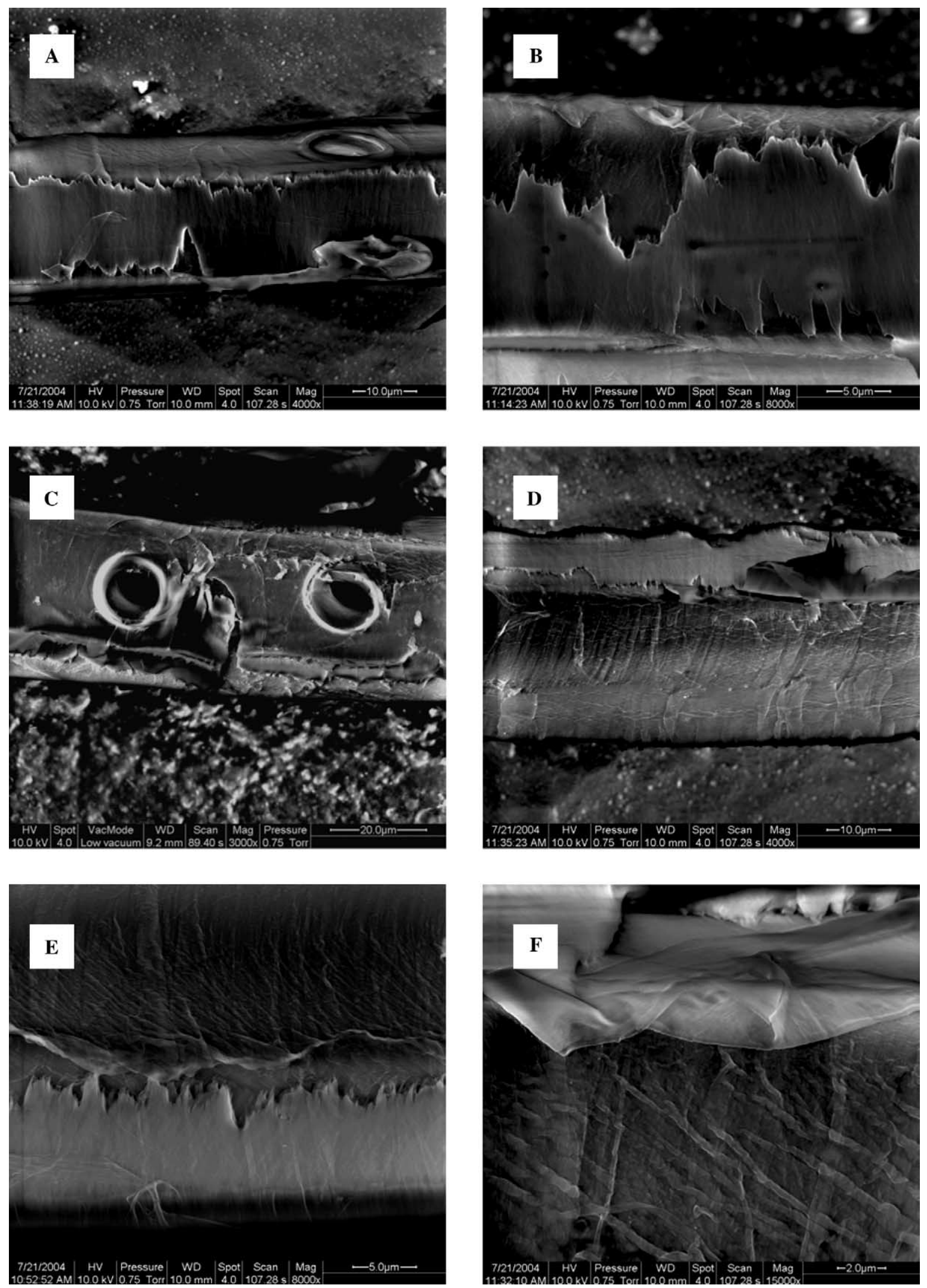

Figure 2 FE-ESEM images in the low-vacuum mode of mechanically isolated spruce fibres shown at various levels of magnification.

clearly shows threads with an orientation parallel to the cell wall axis. Therefore, it seems reasonable to assume that cracks propagated occasionally between the $\mathrm{S} 1$ and S2 layers.

\section{FT-IR microscopy}

The band observed in the $\mathrm{OH}$ valency vibration range between 3700 and $3000 \mathrm{~cm}^{-1}$ was the most intense in 
(A)

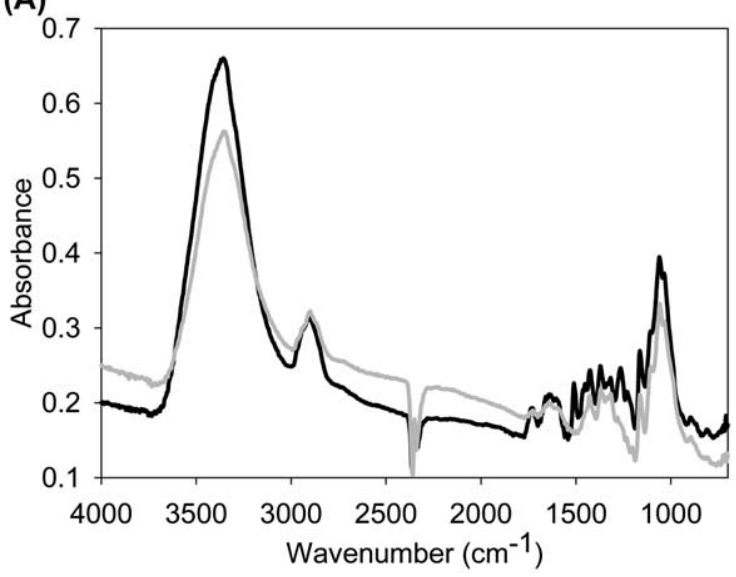

(B)

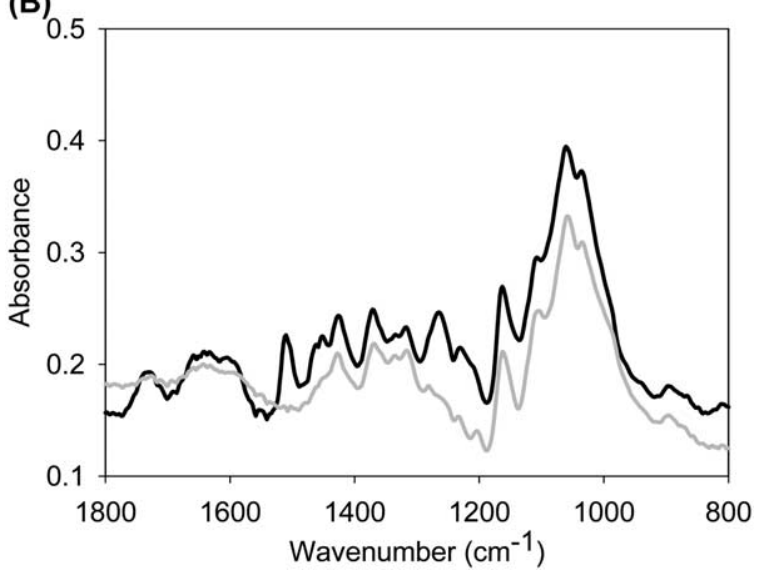

Figure 3 Average FT-IR spectra of mechanically (black line) and chemically (grey line) isolated spruce fibres: (A) full-range spectra of wood fibres; and (B) spectra in the fingerprint area from 1800 to $800 \mathrm{~cm}^{-1}$.

the wood fibre spectra, with a relatively sharp band maximum at $3350 \mathrm{~cm}^{-1}$ (Figure 3A). The band shape and maximum position are the same for fibres from both isolation techniques, whereas the intensity was lower for chemically isolated fibres. The vibration range of the $\mathrm{OH}$ groups shows poor resolution in a conventional IR spectrum of cellulose. However, different technical and mathematical approaches allow attribution of peaks in the range between 3200 and $3400 \mathrm{~cm}^{-1}$ to intermolecular $\mathrm{H}$-bonds between cellulose and in the range 3450-3570 $\mathrm{cm}^{-1}$ to intramolecular $\mathrm{H}$-bonds (Fengel 1993). Lignin, as well as the sample moisture, also gives rise to absorption in the $\mathrm{OH}$ valency range (between 3412 and $3460 \mathrm{~cm}^{-1}$; Hergert 1971, Faix 1991). Olsson and Salmén (2004) found in their water sorption studies on cellulose and hemicelluloses in paper that a peak at $3200 \mathrm{~cm}^{-1}$ may be associated with strongly bound water and a peak at approximately $3600 \mathrm{~cm}^{-1}$ with more loosely bound water. The band at $2902 \mathrm{~cm}^{-1}$ in the $\mathrm{CH}_{2}$ stretching valency range was also less intense for the chemically isolated fibres (Figure 3A). As all three wood polymers and water absorb in the $\mathrm{OH}$ and $\mathrm{CH}$ valency ranges, it is difficult to determine which polymer accounts for the absorbance loss from chemically isolated fibres without analysis of the fingerprint region.
The most intense bands in the fingerprint region are at 1060 and $1035 \mathrm{~cm}^{-1}$ (Figure 3B), attributed to CO stretching vibrations (Fengel and Ludwig 1991). They are of similar or slightly lower intensity for chemically isolated fibres (Figure 3A,B), as are the other carbohydrate bands at $1105 \mathrm{~cm}^{-1}$ (ring asymmetric vibration), $1163 \mathrm{~cm}^{-1}$ (C-O-C asymmetric vibration) and $1317 \mathrm{~cm}^{-1}\left(\mathrm{CH}_{2}\right.$ rocking vibration). These results prove that cellulose is scarcely affected by the maceration process. The greatest differences were observed in the fingerprint region, with the absence of the peak at $1510 \mathrm{~cm}^{-1}$ (aromatic skeletal vibration; Hergert 1971) and $1265 \mathrm{~cm}^{-1}$ (guaiacyl ring breathing with CO stretching; Hergert 1971) for the chemically isolated fibres. From this we conclude that maceration of the fibres leads not only to removal of the lignin-rich middle lamella, but also degrades the aromatic structure of lignin in the secondary cell walls. Degradation of lignin can also be followed in the reduction of the bands at 1603, 1426, 1451 and $1464 \mathrm{~cm}^{-1}$ (Figure 3B). As cellulose and hemicellulose bands are highly overlapped, the decomposition of hemicelluloses is difficult to follow. However, the diminished bands at $1731 \mathrm{~cm}^{-1}(\mathrm{C}=\mathrm{O}$ stretch in unconjugated ketones, carbonyls and ester groups) and at $805 \mathrm{~cm}^{-1}$ (glucomannan; Marchessault 1962) suggest a slight breakdown of hemicelluloses.

In addition, the weight loss caused by the hydrogen peroxide and glacial acetic acid treatment was measured by weighing the wood tissue and the entire fibres after maceration in completely dry conditions. The weight loss of the specimens varied but the examination showed that at least $\sim 35 \%$ of the cell wall material was removed during chemical maceration. The relative volume fraction of lignin in normal adult wood of spruce is approximately 28\% (Fengel and Wegener 1998). Thus, the data obtained by FT-IR microscopy were supported. Even if lignin had been completely removed, a further cell wall component would need to be partly hydrolysed, which was presumably part of the hemicelluloses.

\section{Component considerations}

Electron microscopy studies in the low-vacuum mode and FT-IR microscopy analysis of chemically and mechanically isolated fibres revealed the influence of the isolation technique on structure and polymer assembly. The chemical treatment caused a significant change in polymer assembly in the secondary cell walls. The weight loss examination and FT-IR microscopy analysis showed that the hydrogen peroxide and glacial acetic acid treatment removed lignin to a large extent, whereas hemicelluloses were partially hydrolysed. With regard to the structural composition of chemically isolated fibres, images showed a parallel fibrous texture with an orientation coinciding with the cellulose fibril angle in the secondary cell wall S2. These findings indicate that the decomposition of lignin and hemicelluloses led to significant degradation of the outer cell wall layers (middle lamella, primary wall). However, it seems implausible that the entire S1 layer was removed. One possibility is that the thin S1 layer ( 0.1-0.4 $\mu \mathrm{m}$ thick; Bergander and Salmén 2002; Fengel and Wegener 1998) was extensively degraded, so that the remaining components were flat- 
tened and no longer appeared as an individual layer. An alternative interpretation might be that the parallel fibrous texture along the fibre axis was caused by the shrinkage of the S1-layer (J. Brändström pers. communication). Furthermore, it became obvious in our electron microscopy studies that chemically isolated fibres curled much more extensively than the mechanically isolated fibres. Hence, removal of matrix polymers might cause a loss of tube stability of the single fibre. A more detailed analysis of this phenomenon is given in the second paper of this series (Burgert et al. 2005).

By peeling fibres from the solid wood, the cell wall structure was predominately delaminated between the compound middle lamella and the secondary cell wall layers, both for the fibre of interest and for former matched cells. However, images of the mechanically isolated fibres indicate that cracks also propagated between the S1 and S2 layers. But cracks running transversely into the S2 layer were not observed as a result of the peeling process. It is well known that the S2 layer is the important cell wall layer with regard to mechanical performance (Booker 1996; Reiterer et al. 1999; Bergander and Salmén 2002) and in particular for tensile stress. Hence, the mechanical isolation technique should not significantly alter the microtensile properties of the single fibres. Furthermore, FE-ESEM images showed cell wall segments of former adjacent cells, which were still connected to the isolated fibres. The structure and shape of these cell wall segments make it reasonable to assume that they were pulled out at the cell corners while peeling a single fibre. However, any influence of these additional segments on the mechanical performance of the fibre is unlikely.

Apparently, it would be favourable for investigations into structure-property relationships at the cell and cell wall level to isolate fibres such that they are exclusively separated at the middle lamella and that the cell wall assembly in the primary wall and in the secondary wall remains unmodified. As long as such a method is not at our disposal, the mechanical isolation of fibres seems to be favourable for biomechanical approaches, since the advantage of unmodified cell wall polymers outweighs the disadvantage of fracture in the outer cell wall layers.

\section{Conclusions}

Matched fibres of spruce (Picea abies [L.] Karst.) were isolated both mechanically and chemically from solid wood. Interpreting the structural examination by electron microscopy studies under low-vacuum conditions and chemical analysis by FT-IR-microscopy, the influence of the isolation technique on the fibre properties can be characterised as follows:

\section{Chemically isolated fibres}

- The cell wall polymer assembly was modified.

- Lignin was removed to a large extent and hemicelluloses partly.

- The fibres lost the former tube stability.
- The surface of the chemically isolated fibres showed parallel threads corresponding to the orientation of the cellulose microfibril angle in the S2-layer.

\section{Mechanically isolated fibres}

- The cell wall components were retained unmodified.

- Tube stability and the rectangular shape of the fibres were retained.

- Fracture caused by the peeling process occurred predominately between the compound middle lamella and the $\mathrm{S} 1$ layer, but also between the $\mathrm{S} 1$ and $\mathrm{S} 2$ layers.

- Cracks propagated along the fibre axis; transverse crack propagation into the S2 layer was not observed.

- Segments of the compound middle lamella of former adjacent cells were sometimes adherent to the isolated fibre.

- Since the S2 layer was not damaged, the mechanically isolated fibres are suitable for microtensile investigations.

\section{Acknowledgements}

This work was supported by Fonds zur Förderung der wissenschaftlichen Forschung (FWF). The authors would like to thank Barbara Stefke, Institute of Chemistry, BOKU Vienna, Austria, for working out the details of the chemical maceration of fibres and Dr. Lefteris Paschalis, Ludwig Boltzmann Institute of Osteology, Vienna, Austria, for providing access to the FT-IR microscope.

\section{References}

Ander, P. and K. Nyholm. 2000. Deformations in wood and spruce pulp fibres: their importance for wood and pulp properties. In: Proceedings of the International Symposium on Wood Machining. Eds. S.E. Stanzl-Tschegg and A. Reiterer. CD Laboratory for Fundamentals of Wood Machining, Vienna, Austria. pp. 3-19.

Bergander, A. and L. Salmén. 2002. Cell wall properties and their effects on the mechanical properties of fibers. J. Mater. Sci. $37,151-156$.

Bodig J. and B.A. Jayne. 1982. Mechanics of Wood and Wood Composites. Van Nostrand Reinhold, New York.

Booker, R.E. 1996. The reasons for the microfibril orientations in the tracheid cell walls of trees. In: Donaldson, L.A., A.P. Singh, B.G. Butterfield and L.J. Whitehouse (Eds.) Recent Advances in Wood Anatomy. Forest Research Institute, New Zealand. pp. 273-282.

Burgert, I. and K. Frühmann. 2004. Micromechanics of wood structure-function relationships at the tissue and fiber level. In: Salmén L. (Ed.) Proceedings of the $2^{\text {nd }}$ International Conference of the European Society for Wood Mechanics, Stockholm, Sweden. pp. 153-162.

Burgert, I., J. Keckes, K. Frühmann, P. Fratzl and S.E. Tschegg. 2002. A comparison of two techniques for wood fiber isolation - evaluation by tensile tests on single fibres with different microfibril angle. Plant Biol. 4, 9-12.

Burgert, I., K. Frühmann, J. Keckes, P. Fratzl and S.E. Tschegg. 2003. Microtensile testing of wood fibers combined with video extensometry for efficient strain detection. Holzforschung $57,661-664$. 
Burgert, I., K. Frühmann, J. Keckes, P. Fratzl and S. StanzlTschegg. 2004. Properties of chemically and mechanically isolated fibres of spruce (Picea abies [L.] Karst.). Part 2: Twisting phenomena. Holzforschung 59, 247-251.

Donaldson, L.A. 1995. Cell wall fracture properties in relation to lignin distribution and cell dimensions among three genetic groups of radiate pine. Wood Sci. Technol. 29, 51-63.

Faix, O. 1991. Classification of lignins from different botanical origins by FTIR spectroscopy. Holzforschung 45(Suppl.), 21-27.

Fengel, D. 1993. Influence of water on the $\mathrm{OH}$ valency range in deconvoluted FTIR spectra of cellulose. Holzforschung 47, 103-108.

Fengel, D. and M. Ludwig. 1991. Möglichkeiten und Grenzen der FTIR-Spektroskopie bei der Charakterisierung von Cellulose. Teil 1. Vergleich von verschiedenen Cellulosefasern und Bakterien-Cellulose. Das Papier 45, 45-51.

Fengel, D. and G. Wegener. 1984. Wood - Chemistry, Ultrastructure, Reactions. De Gruyter, Berlin, New York.

Fratzl, P. 1999. Biologische Materialien - dem Bauplan natürlicher Hochleistungswerkstoffe auf der Spur. Phys. Zeit 30, 196-200.

Fratzl, P. 2003. Cellulose and collagen: from fibres to tissues. Curr. Opin. Colloid Interface Sci. 8, 32-39.

Groom L., L. Mott and S.M. Shaler. 2002a. Mechanical properties of individual southern pine fibers. Part I. Determination and variability of stress-strain curves with respect to tree height and juvenility. Wood Fiber Sci. 34, 14-27.

Groom L., S. Shaler and L. Mott. 2002b. Mechanical properties of individual southern pine fibers. Part III. Global relationships between fiber properties and fiber location within an individual tree. Wood Fiber Sci. 34, 238-250.

Hergert, H.L. 1971. Infrared spectra. In: Sarkanen K.V. and C.H. Ludwig (Eds.) Lignins. Occurrence, Formation, Structure and Reactions. John Wiley \& Sons, New York, Chichester, Brisbane, Toronto, Singapore. pp. 267-297.

Jayne, B.A. 1959. Mechanical properties of wood fibres. Tappi $42,461-467$.

Jayne, B.A. 1960. Some mechanical properties of wood fibres in tension. For. Prod. J. 10, 316-322.

Jeronimidis, G. 2000. Structure-property relationships in biological materials. In: Elices, M. (Ed.) Structural Biological Materials. Pergamon Materials Series. Elsevier Science, Oxford. pp. 3-16.

Kataoka, Y., H. Saiki and M. Fujita. 1992. Arrangement and superimposition of cellulose microfibrils in the secondary walls of coniferous tracheids. Mokuzai Gakkaishi 38, 327-335.

Keckes, J., I. Burgert, K. Frühmann, M. Müller, K. Kölln, M. Hamilton, M. Burghammer, S.V. Roth, S.E. Stanzl-Tschegg and P. Fratzl. 2003. Cell-wall recovery after irreversible deformation of wood. Nat. Mater. 2, 810-814.
Lichtenegger, H.C., M. Müller, R. Wimmer and P. Fratzl. 2003. Microfibril angles inside and outside crossfields of Norway spruce tracheids. Holzforschung 57, 13-20.

Lindström, H., J.W. Evans and S.P. Verrill. 1998. Influence of cambial age and growth conditions on microfibril angle in young Norway spruce (Picea abies [L.] Karst.). Holzforschung 52, 573-581.

Marchessault, R.H. 1962. Application of infra-red spectroscopy to cellulose and wood polysaccharides. Pure Appl. Chem. 5, 107-129.

Meylan, B.A. and B.G. Butterfield. 1978. Helical orientation of the microfibrils in tracheids, fibres and vessels. Wood Sci. Technol. 12, 219-222.

Mott, L., S.M. Shaler, L.H. Groom and B.H. Liang. 1995. The tensile testing of individual wood fibre using environmental scanning electron microscopy and video image analysis. Tappi 78, 143-148.

Mott L., L. Groom and S. Shaler. 2002. Mechanical properties of individual southern pine fibers. Part II. Comparison of earlywood and latewood fibres with respect to tree height and juvenility. Wood Fiber Sci. 34, 221-237.

Nyholm, K., P. Ander, S. Bardage and G. Daniel. 2001. Dislocations in pulp fibres - their origin, characteristics and importance - a review. Nord. Pulp Paper Res. J. 4, 376-384.

Olsson, A.M. and L. Salmén. 2004. The association of water to cellulose and hemicellulose in paper examined by FTIR spectroscopy. Carbohyd. Res. 339, 813-818.

Page D.H. and F. El-Hosseiny. 1983. The mechanical properties of single wood pulp fibres. Part Vl. Fibril angle and the shape of the stress-strain curve. J. Pulp Paper Sci. 9, 1-2.

Page D.H., F. El-Hosseiny, K. Winkler and A.P.S. Lancaster. 1977. Elastic modulus of single wood pulp fibres. Tappi 60 , 114-117.

Reiterer A., H. Lichtenegger, S. Tschegg and P. Fratzl. 1999. Experimental evidence for a mechanical function of the cellulose microfibril angle in wood cell walls. Philos. Mag. A 79, 2173-2184.

Sedighi-Gilani, M. and P. Navi. 2004. Influence of local variation of microfibril angle on tensile behaviour of individual wood fibers. In: Stanzl-Tschegg, S.E., M. Gindl and G. Sinn (Eds.) Proceedings of the $2^{\text {nd }}$ International Symposium on Wood Machining. BOKU, Vienna. pp. 27-35.

Shaler, S.M., L.H. Groom and L. Mott. 1996. Microscopic analysis of wood fibres using ESEM and confocal microscopy. In: Woodfiber/Plastic Composites: Virgin and Recycled Wood Fibre and Polymers for Composites, Proceedings No 7293, May 1-3, 1995, Madison, WI. pp. 25-32.

Received May 5, 2003. Accepted October 20, 2004. 